\title{
SM Otolaryngology Cochlear Implantation in Far Advanced Otosclerosis: A Case Report
}

\author{
Rogério Hamerschmidt ${ }^{1}$, Gislaine Richter ${ }^{1}$, Adriana Kosma Pires de Oliveira ${ }^{2}$, \\ Mohamad Feras Al-Lahham ${ }^{2 *}$ and Valéria Kutianski ${ }^{1}$ \\ ${ }^{1}$ Departament of ENT, Federal University of Paraná, Physician of Instituto Paranaense de \\ Otorrinolaringologia, Brasil \\ ${ }^{2}$ ENT Physician, Instituto Paranaense de Otorrinolaringologia, Brasil
}

\begin{abstract}
Article Information
Received date: Jul 01, 2017

Accepted date: Jul 19, 2017

Published date: Jul 25, 2017

*Corresponding author
\end{abstract}

Mohamad Feras Al-lahham, ENT Physician, Otorhinolaryngologist, Instituto paranaense de otorrinolaringologia, Curitiba - Paraná, Brasil,

Tel: +55 41995614955 ;

Email: dr_lahham@hotmail.com

Distributed under Creative Commons CC-BY 4.0

Keywords Cochlear implant;

Otosclerosis; Sensorineural hearing loss

Article DOI 10.36876/smotol.1007

\section{Introduction}

The term far-advanced otosclerosis was introduced by House and Sheehy [1] to indicate clinical otosclerosis with air conduction thresholds of more than $85 \mathrm{~dB}$ HL, Theotosclerotic process commonly involves the otic capsule and may cause quite widespread demineralisation which leads to a progressive and often profound bilateral sensorineural hearing loss.

A definitive diagnosis of cochlear otosclerosis can be established when high-resolution CT scans show the appearance of a bony lucency forming the characteristic "double ring", which is thought to reflect demineralized foci of active otosclerosis [2]. Moreover, sclerotic foci may narrow the cochlear turns, which can be mostly seen at the basal turn [2] Ossification of the cochlea was once considered to be a contraindication for cochlear implantation.

Till recently, stapedectomy and subsequent hearing aid fitting has been the standard approach for patients with far-advanced otosclerosis, $[3,4]$ but recently cochlear implantation has proved to yield better hearing and communicative skills [5]. Cochlear Implantation (CI) is a highly successful technique of improving severe and profound hearing loss.

Facial Nerve Stimulation (FNS) is when the current from the CI electrode unintentionally stimulates the facial nerve causing facial twitching or paraesthesia [6].

\section{Case Report}

A 44 year-old male came to our hospital complaining of hearing impairment on both sides that had started several years ago. The hearing loss first began 20 years ago on the left side and the hearing on the right side started to deteriorate 10 years ago. He had no other medical disease or any family history of hearing loss. On physical examination, the tympanic membrane was intact on both sides without any evidence of Schwartze sign. Pure tone audiometry demonstrated profound sensorineural hearing loss on the both sides (Figure 1). The speech discrimination score preopertavely was: the right ear without any response, the left ear with a response below $60 \%$ in speech discrimination tests.

Since a large air-bone gap of $40 \mathrm{~dB}$ HL was detected on the both sides, high resolution temporal bone CT was performed. On images, low density was identified at fissula ante fenestram and around the vestibule bilaterally, and double ring effect of the cochlea was seen on both sides (Figure 2).

\section{The role of Rotoveel computed tomography imaging and grading:}

Otosclerosis is categorised into two types, fenestral and retrofenestral. Imaging plays an important role in the diagnosis and management of otosclerosis. High-Resolution CT (HRCT)

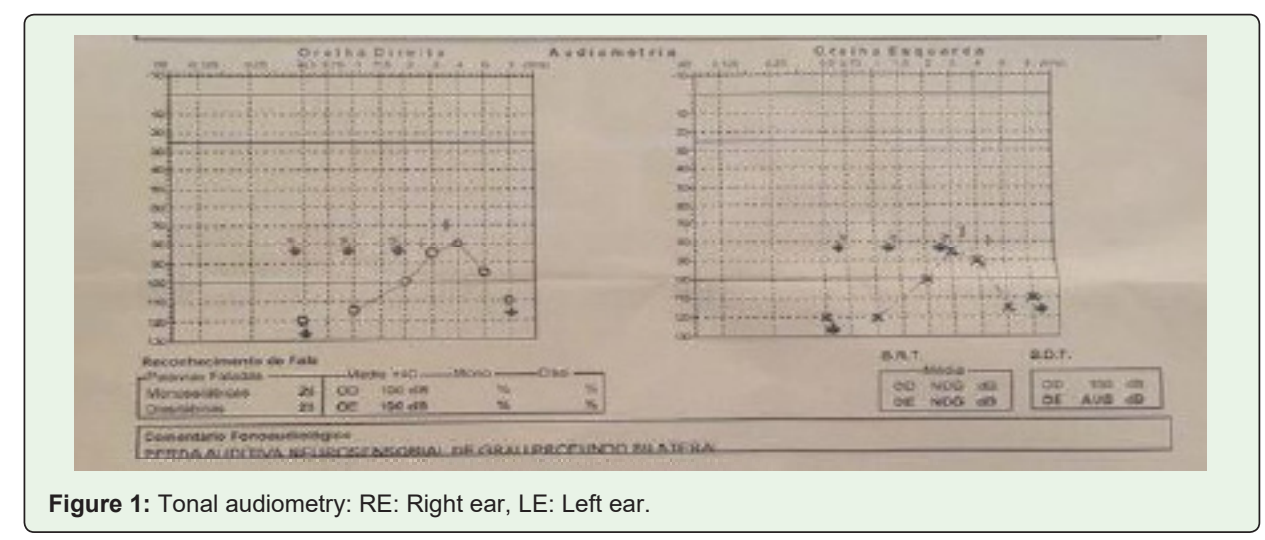

Figure 1: Tonal audiometry: RE: Right ear, LE: Left ear

\section{OPEN ACCESS}

ISSN: 2574-2418 


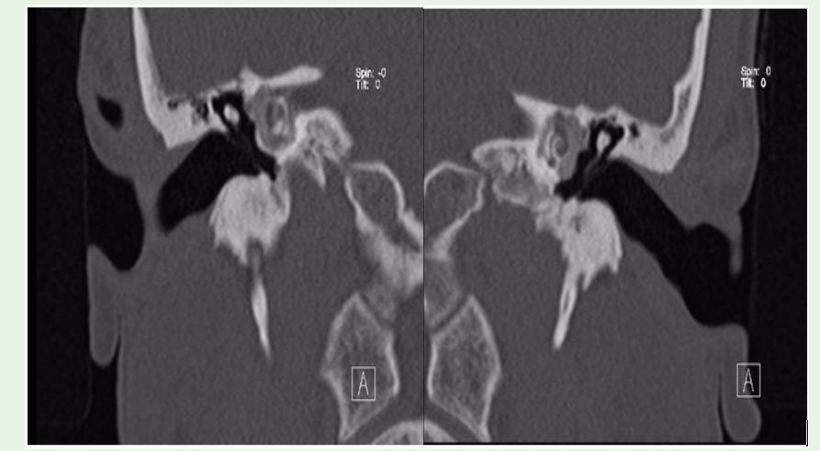

Figure 2: Computed tomography of ears, coronal section.1- cochlea, 2osseous spiral lamina 3- malleus head 4- external auditory canal.

of the temporal bone using $1 \mathrm{~mm}$ (or less) thick sections is the modality of choice for assessment of the labyrinthine windows and cochlear capsules. MRI has limited application in the evaluation of the labyrinthine capsules but is useful for assessment of the cochlear lumen prior to cochlear implantation in patients with profound hearing loss. The treatment of fenestral otosclerosis is primarily surgical with stapedectomy and prosthesis insertion. Patients with retrofenestral otosclerosis and profound hearing loss are treated medically using fluorides, but may derive significant benefit from cochlear implantation. Various authors have used different CT grading systems for the classification of advanced otosclerosis. The CT grading system of Rotoveel is partially based on the location and type of the lesion: solely fenestral (grade 1), retrofenestral: double ring or halo effect (grade 2A), narrowed basal turn (grade 2B) or both (grade $2 \mathrm{C}$ ), and diffuse confluent retrofenestral involvement (grade 3). One disadvantage of the Rotoeveel classification is that subtle erosions around the cochlea are not possible to classify because only a double ring or a narrowed basal turn are included. We prefer to use Rotoveel classification in our algorithm because we believe that the type of the lesion is of greater influence on the success rate of CI than the location of the lesion. Subtle erosions in the cochlea, without basal turn narrowing or the halo effect are not likely to cause considerable problems during electrode insertion.

The rotoveel computed tomography CT grading of the otosclerotic foci was grade III, with diffuse confluent cochlear involvement with an unrecongnizable cochlea.

Considering that the patient gained limited benefit with hearing aids, cochlear implantation was performed. On preoperative speech evaluation, the aided open-set sentence score in auditory-only

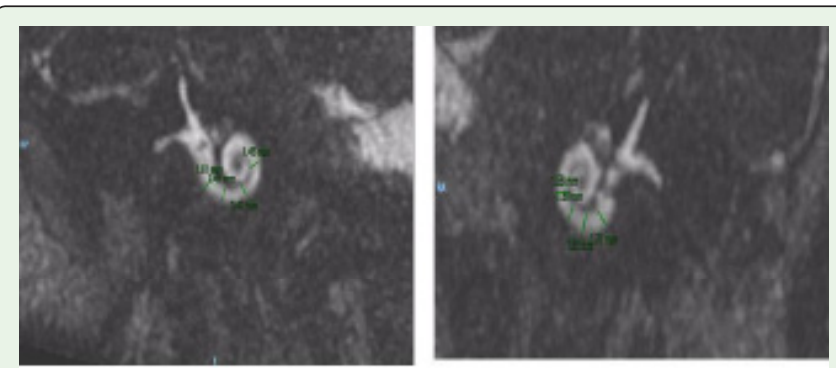

Figure 3: magnetic resonance of both ears: 1- coclea 2- auditive nerve

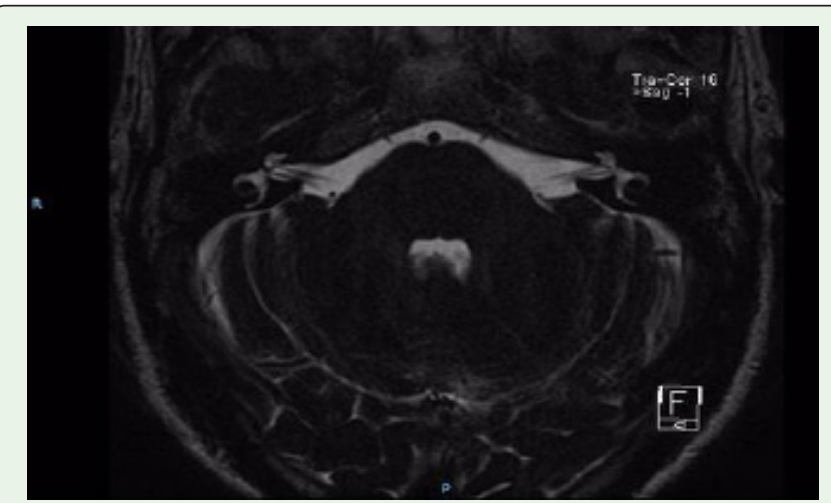

Figure 4: magnetic resonance of internal auditory canal: 1- cochleovestibular nerve.

condition was $40 \%$. The patient did not complain of dizziness or unsteadiness.

Brain Magnetic Resonance Imaging (MRI) was performed for the evaluation of cochlear nerve integrity and patency of the cochlea. The cochleovestibular nerve was normally identified within the internal auditory canal on the parasagittal view and there was no sign of obliteration of the cochlear turns on MRI (Figures 3 and 4). Despite the use of hearing aid on the both sides, the patient's hearing had worsened progressively and the patient had great difficulty in everyday communication even with lip-reading.

Intraoperatively, hypervascularization was observed on the promontory and round window niche. The patient was implanted with CI422 device with perimodiolar type electrode. Complete insertion of electrode was achieved without resistance and no perilymphatic gusher was encountered. Intraoperative impedanciometry response revealed a good response in all of the 22 electrodes. Intraoperative Neural Response Telemetry (NRT) revealed response just in electrode number [7]. The device was switched-on at postoperative one month 937 pulse, 900 rate), and NRT demonstrated good responses in the basal, middle, and apical electrodes. Facial twitching was observed during electrical stimulation on eletretodes $[6,8,9]$. The sound field test using the cochlear implant device demonstrated pure tone threshold of $20 \mathrm{~dB}$ HL 2 months after switch-on. On speech evaluation, monosyllabic and disyllable word discrimination scores reached $100 \%$ and $80 \%$, respectively, 06 months after switch-on. The open-set sentence score improved from $60 \%$ preoperatively to $90 \% 6$ months after switch-on and this improvement has been maintained until the last evaluation performed 6 months after switch-on. The auditory performance improved dramatically 6 months after switchon and telephone conversation was possible using the cochlear implant alone.

In the follow up period, we had a good response in the activation of all the electrodes (37 pulses, with a rate of 900).

\section{Discussion}

The patient with far advanced otosclerosis derives significant benefit from cochlear implantation [8]. This report presents a case of successful CI without any intraoperative or postoperative complications performed in a patient with far-advanced otosclerosis. Auditory rehabilitation in otosclerosis can be achieved by various 
approaches including hearing aids, stapes surgery, or CI. Stapes surgery and hearing aid amplification might be initially considered in patients who still have residual hearing and measurable bone conduction since stapedotomy is a safe, simple, and low-cost procedure [8].

There are several complicating factors that need consideration in performing $\mathrm{CI}$ in otosclerosis. There is a greater chance of partial insertion or misplacement of the electrode array because of the severely thinned and distorted otic capsule in advanced stages of otosclerosis.

In otosclerosis, the pathologic condition is mainly present in the lateral wall of the cochlea and leaves the auditory nerve uninvolved Fayad et al. [7] estimated the number of spiral ganglion cells in seven temporal bones with otosclerosis, and found a sufficient (40\% to $85 \%$ of normal) number of cells for successful electrical stimulation.

The presence of radiographic abnormalities did not predict hearing outcome [10].

In far-advanced otosclerosis, surgical implantation may be complicated by ossification of the cochlea, which can be reliably detected on preoperative CT scans. This ossification may impair the insertion of the electrodes. In our case there was no difficulty in the insertion of all the electrodes.

Facial Nerve Stimulation is a well-known adverse effect of cochlear implants. In far-advanced otosclerosis, the reported incidence of FNS in cochlear implant recipients varies widely from $17 \%$ to $78 \%$. FNS has been reported to occur as a result of an electrical shunt between the cochlear ducts and the facial nerve [11]. The massive bone resorption in otosclerosis and a gradual thinning of the bone between the facial nerve and cochlea might contribute to this shunt. Marshal et al. [12] demonstrated that severity of bone resorption on CT scans is correlated with the likelihood on FNS. Surgical methods were also advocated to resolve the facial nerve stimulation such as the use of a perimodiolar hugging electrode array in order to place the electrode as close as possible to the auditory nerve resulting in lower T- and C-thresholds [10] or the reimplantation with newer devices [13].

Our patient did not present VII pair alterations.

\section{Conclusion}

Patients suffering from far-advanced otosclerosis may benefit from cochlear implantation with performance scores comparable to non-otoscleroticimplantees. The surgeon should be aware that extensive otosclerotic bone resorption on CT scans might predict difficulties during electrode insertion and higher probability on FNS. Moreover, FNS can mostly be overcome by appropriate resetting of the current levels for comfort level without affection overall speech discrimination performance.

\section{References}

1. House HP, Sheehy JL. Stapes surgery: selection of the patient. Ann Oto Rhinol Laryngol. 1961; 70: 1062-1068.

2. Thiers FA, Valvassori GE, Nadol JB Jr. Pathology case of the month: otosclerosis of the cochlear capsule: correlation of computerized tomography and histopathology. Am J Otol. 1999; 20: 93-95.

3. Glasscock ME, Storper IS, Haynes DS, Bohrer PS. Stapedectomy in profound cochlear loss. Laryngoscope. 1996; 106: 831-833.

4. Iurato S, Ettorre GC, Onofri M, Davidson C. Very far-advanced otosclerosis. Am J Otol. 1992; 13: 482- 487.

5. Berrettini S, Burdo S, Forli F, Ravecca F, Marcaccini M, Casani AP, et al. Far advanced otosclerosis: stapes surgery or cochlear implantation? J Otolaryngol. 2004; 33: 165-171.

6. Broomfield S, Mawman D, Woolford TJ, O'driscoll M, Luff D, Ramsden RT. Non-auditory stimulation in adult cochlear implant users. Cochlear Implants Int. 2000; 1: 55-66

7. Parahy C, Linthicum FH Jr. Otosclerosis: relationship of spiral ligament hyalinization to sensorineural hearing loss. Laryngoscope. 1983; 93: 717 720.

8. Park, kC, Shim DB, Moon IS, Song MH. Cochlear Implantation in a Patient with Advanced Otosclerosis. Korean J Otorhinolaryngol-Head Neck Surg. 2013; 56: 667-670.

9. Merkus $\mathrm{P}$, van Loon MC, Smit CF, Smits C, de Cock AF, Hensen EF Decision making in advanced otosclerosis: an evidence-based strategy. Laryngoscope. 2011; 121: 1935-1941.

10. Semaan MT, Gehani NC, Tummala N, Coughlan C, Fares SA, Hsu DP, et al Cochlear implantation outcomes in patients with far advanced otosclerosis. Am J Otolaryngol. 2012; 33: 608-614.

11. Polak M, Ulubil SA, Hodges AV, Balkany TJ. Revision cochlear implantation for facial nerve stimulation in otosclerosis. Arch Otolaryngol Head Neck Surg. 2006; 132: 398-404.

12. Marshall AH, Fanning N, Symons S, Shipp D, Chen JM, Nedzelski JM. Cochlear implantation in cochlear otosclerosis. Laryngoscope. 2005; 115: 1728-1733.

13. Battmer R, Pesch J, Stöver T, Lesinski-Schiedat A, Lenarz M, Lenarz T. Elimination of facial nerve stimulation by reimplantation in cochlear implant subjects. Otol Neurotol. 2006; 27: 918-922. 